\title{
Maternal and infant vitamin D status during lactation: Is latitude important?*
}

\author{
Carol L. Wagner ${ }^{1 \#}$, Cynthia R. Howard ${ }^{2}$, Thomas C. Hulsey ${ }^{1}$, Ruth A. Lawrence ${ }^{2}$, Myla Ebeling ${ }^{1}$, \\ Judy Shary ${ }^{1}$, Pamela G. Smith ${ }^{1}$, Kristen Morella ${ }^{1}$, Sarah N. Taylor ${ }^{1}$, Bruce W. Hollis ${ }^{1}$ \\ 'Department of Pediatrics, Medical University of South Carolina, Charleston, South Carolina, USA; \\ ${ }^{\#}$ Corresponding Author: wagnercl@musc.edu \\ ${ }^{2}$ Department of Pediatrics, University of Rochester, Rochester, New York, USA
}

Received 25 October 2013; revised 26 November 2013; accepted 2 December 2013

Copyright (C) 2013 Carol L. Wagner et al. This is an open access article distributed under the Creative Commons Attribution License, which permits unrestricted use, distribution, and reproduction in any medium, provided the original work is properly cited.

\section{ABSTRACT}

Background: The effect of latitude on maternal and infant vitamin $D$ status during lactation is presumed to be strongly associated with higher rates of deficiency in those living at higher latitudes, yet with lifestyle changes, this conclusion may no longer be correct. Objective: To ascertain if higher latitude adversely affects the vitamin D status of lactating women and their fully breastfeeding infants. Study Design/Methods: Fully breastfeeding women and their infants were eligible for participation in this study as part of a larger prospective vitamin $D$ supplementation trial. Women were recruited from two sites of differing latitude: Charleston, $\mathrm{SC}$ at $32^{\circ} \mathrm{N}$ and Rochester, NY at latitude $43^{\circ} \mathrm{N}$. Maternal and infant baseline vitamin D status, intact parathyroid hormone (IPTH), serum calcium and phosphorus as a function of site/latitude were measured. The primary outcome was maternal and infant total circulating 25(OH)D at baseline by center/latitude, and the secondary outcome was the percent of women and infants who had achieved a baseline concentration of at least $20 \mathrm{ng} / \mathrm{mL}$, meeting the Institute of Medicine's definition of sufficiency at 4 to 6 weeks postpartum. Statistical analysis was performed using SAS version 9.3. Results: Higher latitude adversely affected vitamin D status only in lactating Caucasian women. African American and Hispanic women and infants living in Rochester compared to Charleston had improved vitamin D status, an effect that was no longer significant when controlling for

"Funded in part by NIH/NICHD R01HD047511, NIH UL 1 RR029882, and the Medical University of School Carolina's Children's Hospital Fund. socioeconomic factors and season. Overall, there was a significant vitamin $D$ deficiency at baseline in lactating mothers, and a far greater deficiency in their infants. Maternal baseline 25(OH)D concentration remained positively associated with being Caucasian, BMI and summer months. Breastfeeding infant vitamin D status mirrored maternal status and remained positively associated with being Caucasian and summer months. Those infants who had been on a vitamin D supplement at the time of enrollment in the study had markedly improved vitamin D status compared to those infants not on supplement, but represented a significant minority of the cohort. Conclusions: There was a significant vitamin $\mathrm{D}$ deficiency among a cohort of women and their infants living at two diverse latitudes-Charleston, SC and Rochester, NY. Given the higher rate of vitamin D deficiency among African American and Hispanic women and their infants living at a lower latitude, conclusions about vitamin D status based on latitude alone may be faulty.

Keywords: Vitamin D; Cholecalciferol; Lactation; Latitude

\section{INTRODUCTION}

While several factors impact on vitamin D status: skin pigmentation, body mass index, latitude, sunlight exposure, and dietary intake, it is sunlight exposure and the angle of the sun, both dependent on the time of the year and latitude that are the most critical [1-3]. Latitude is a key factor frequently identified as a strong influence on an individual's vitamin D status, with lower vitamin D status as measured by total circulating $25(\mathrm{OH}) \mathrm{D}$ concentration in those living at higher latitudes compared with those 
living closer to the equator [1,3-5]. Thus, individuals living in northern climes in the Northern hemisphere and southern climes in the Southern hemisphere are identified as being at higher risk of vitamin D deficiency than those living closer to the equator. While higher latitude has been shown to be an independent risk factor for vitamin D deficiency [1-3], with changes in lifestyle, it is unclear if this association persists in the $21^{\text {st }}$ century in urban settings.

Recent data suggest that deficiency is no longer limited to higher latitudes, with reports of deficiency in more than $75 \%$ of pregnant African American women living at $32^{\circ} \mathrm{N}$ in South Carolina with expected parallels of such deficiency noted in their newborn infants [6-8]. In another region of the world, similar trends were reported by Halicioglu et al. in their recent report of vitamin D status in 4-month-old exclusively breastfed infants living in Izmir, Turkey at $38.25^{\circ} \mathrm{N}$ : Despite receiving $400 \mathrm{IU}$ vitamin $\mathrm{D} /$ day, the rate of vitamin $\mathrm{D}$ deficiency (defined as a $25(\mathrm{OH}) \mathrm{D}$ concentration $\leq 20 \mathrm{ng} / \mathrm{mL})$ among these exclusively breastfed infants was $28 \%$ overall increasing to $56 \%$ during the winter months. Given lifestyle pattern changes in the past two decades, the question remains if latitude plays a significant role in vitamin D status today as it did in the past in lactating women and their infants, and if so, what are mitigating factors that impact on that relationship.

The lactating mother-infant dyad has been singled out as particularly vulnerable to vitamin D deficiency, chiefly affecting those with darker pigmentation or limited access to sunlight exposure $[9,10]$. Maternal vitamin D status during pregnancy predicts fetal and therefore neonatal vitamin D status [11-13]. It has been known for some time that exclusively breastfeeding infants are dependent on maternal transfer of vitamin D in their milk. If a mother is vitamin $\mathrm{D}$ deficient then her milk will have diminished antirachitic activity, and therefore, her breastfeeding infant will be deficient in vitamin D [10,11,14-16]. Because of this, more attention has been given to assessing the vitamin D status of breastfed infants, with the 2008 American Academy of Pediatrics' recommendation that all breastfed infants receive vitamin D supplementation of $400 \mathrm{IU} /$ day starting within a few days of birth [9]. Despite the fact that maternal vitamin D status predicts milk antirachitic activity [10,11,14-16], historically human milk has been considered a poor source of vitamin D for the breastfeeding infant [9]: milk antirachitic activity is reported between 20 - 70 IU/liter breast milk with no mention of maternal vitamin D status' effect on antirachitic activity of breast milk $[9,17]$.

To ascertain if latitude affects the vitamin D status of lactating women, as part of a two-center NICHD-sponsored vitamin D supplementation during lactation trial, the baseline vitamin $\mathrm{D}$, intact serum parathyroid hormone
(iPTH) and serum calcium and phosphorus status at fourto-six weeks' postpartum in fully lactating women and their infants enrolled in the study were measured. It was hypothesized that women and their fully breastfeeding infants living at latitude $43^{\circ} \mathrm{N}$ in Rochester, NY, would have lower total circulating 25-hydroxy-vitamin D $(25(\mathrm{OH}) \mathrm{D})$ and higher iPTH concentrations than women and their fully breastfeeding infants living at latitude $32^{\circ} \mathrm{N}$ in Charleston, SC. The results of the baseline characteristics and vitamin D-related laboratory data of this cohort from two distinct latitudes and diverse racial/ethnic backgrounds are presented here.

\section{METHODS}

\subsection{Subjects}

Approval for this study was granted by: (1) the Medical University of South Carolina's (MUSC) Institutional Review Board for Human Subjects, HR \#11345 and MUSC's Clinical and Translational Research Center (CTRC; Protocol \#752); and (2) the University of Rochester's (U of R) Institutional Review Board for Human Subjects (\#14460) and University of Rochester's CTRC (Protocol \#1129). The study was registered via ClinicalTrial.gov \#NCT00412074.

\subsection{Study Settings}

Charleston, South Carolina, USA: The subjects were recruited from the Charleston, South Carolina's metropolitan area on the coast of the Atlantic Ocean at latitude $32.78^{\circ} \mathrm{N}$. Charleston is the oldest and second-largest city in the southeast region of the United States, with a 2010 census population of 120,080 in the city proper and an estimated population in the surrounding metropolitan tri-county area in 2012 of 697,439 - the second largest in the state - and the 78th-largest metropolitan statistical area in the United States.

Rochester, New York, USA: The subjects also were recruited from Rochester, New York's metropolitan area, an urban area on the shores of Lake Ontario with Canada to the North at latitude $43.15^{\circ} \mathrm{N}$, the third largest city in New York, with a 2010 census population of approximately 210,565 and an estimated population in the surrounding metropolitan area of 1,079,671 people.

\subsection{Inclusion Criteria}

(a) Fully lactating mothers and their breastfeeding infants within 4-to-6 weeks' postpartum living in Charleston, SC or Rochester, NY were eligible for inclusion in the study if they planned to continue full breastfeeding for the next 6 months. The study was conducted at the Medical University of South Carolina (MUSC) and the University of Rochester (U of R). 
(b) Infants had to be at least 35 weeks of gestation or greater and in good general health at the time of enrollment. Infants receiving a vitamin D supplement prior to the study were eligible for participation in the study (their results are reported separately).

\subsection{Exclusion Criteria}

(a) Mothers were not eligible for participation in the study if they had any of the following diagnoses: preexisting type I or II diabetes, hypertension, parathyroid disease, and uncontrolled thyroid disease.

(b) Infants $<35$ weeks of gestation; with a history of $>$ 72 hours in the neonatal intensive care unit; any inborn error of metabolism; history of congenital anomalies; or a history of consuming more than $10 \%$ of their diet as formula at the time of enrollment were not eligible for participation in the study.

\subsection{Study Protocol}

Visit: Each lactating mother and her breastfeeding infant came to the Clinical and Translational Research Center (CTRC) at MUSC or University of Rochester for the baseline visit at 4 to 6-weeks' postpartum.

Completion of questionnaires: Questionnaires regarding sociodemographic information including extent of education (stratified by less than high school vs. at least high school) and insurance status (private vs. Medicaid/ none), baseline health status, and medical history were completed at the first baseline visit and are reported here. Each mother also was asked to provide a breastfeeding history. Only women who were fully breastfeeding [18, 19] were eligible to participate in the lactation arm of the study.

Blood Sample Collection: A baseline blood sample was drawn from each mother and infant to measure total circulating $25(\mathrm{OH}) \mathrm{D}(\mathrm{ng} / \mathrm{mL})$, intact parathyroid hormone $(\mathrm{pg} / \mathrm{mL})$, total serum calcium $(\mathrm{mg} / \mathrm{dL}]$ and total serum phosphorus $(\mathrm{mg} / \mathrm{dL})$.

\subsection{Measures}

Maternal Sociodemographic Measures included maternal age at time of enrollment, her self-defined race, insurance status (private or Medicaid/uninsured), educational status (in years of education), and occupation.

Maternal Weight and Height: Each mother's weight was recorded in $\mathrm{kg}$ at the visit. Her height was measured in $\mathrm{cm}$ and converted to meters $(\mathrm{m})$. Her body mass index (BMI) was calculated as follows: weight $(\mathrm{kg}) /[$ height (m) $]^{2}$.

Infant Gestational Age, Birth Weight, Current Weight, Current Length and Current Head Circumference: The gestational age at birth (in weeks) and the birth weight (grams) of each infant were recorded at the time of en- rollment based on maternal report that was later verified by maternal and infant medical records. Each infant's current weight $(\mathrm{kg})$, length $(\mathrm{cm})$ using a length board, and head circumference $(\mathrm{cm})$ were measured according to standard clinical pediatric practice at the initial baseline visit.

Infant Vitamin D Supplementation: At the time of the initial visit, whether or not the infant was receiving a vitamin D oral supplement along with the number of international units (IU) per day were recorded.

\subsection{Laboratory Measures}

Total Circulating 25(OH)D Concentration: Baseline total circulating $25(\mathrm{OH}) \mathrm{D}$ concentration expressed in $\mathrm{ng} / \mathrm{mL}$ in maternal and infant serum samples was used as the indicator of vitamin D status and was measured by RIA (Diasorin, Inc.) as previously described [20]. This RIA is an FDA-cleared device and, in fact, is the FDA predicate device for the measurement of circulating $25(\mathrm{OH}) \mathrm{D}$ in humans. Based on clinical laboratory classifications for both mothers and infants [21,22], a priori, deficiency was defined as total circulating $25(\mathrm{OH}) \mathrm{D}<50$ $\mathrm{nmol} / \mathrm{L}(20 \mathrm{ng} / \mathrm{mL})$, insufficiency as $\geq 50$ to $<80 \mathrm{nmol} / \mathrm{L}$ $(\geq 20$ to $<32 \mathrm{ng} / \mathrm{mL})$, and sufficiency as $\geq 80 \mathrm{nmol} / \mathrm{L}(\geq 32$ $\mathrm{ng} / \mathrm{mL})[11,22,23]$. The inter- and intra-assay coefficient of variation is $\leq 10 \%$.

Maternal and Infant Circulating intact PTH Concentrations: Intact PTH (iPTH) was measured by immunoradiometric (IRMA) that utilizes 2 different polyclonal antibodies (Diasorin, Stillwater, MN). The first antibody, specific for PTH 39 - 84, is bound to a solid phase bead. The second antibody is specific for PTH 1-34 and is labeled with ${ }^{125} \mathrm{I}$. The adult and infant normal range for iPTH in our laboratory is $13-54 \mathrm{pg} / \mathrm{mL}(1.3-5.4$ $\mathrm{pmol} / \mathrm{L})$. Higher vitamin D levels are associated with lower iPTH; as vitamin D status improves iPTH declines [24].

Maternal and Infant Baseline Serum Calcium and Phosphorus Studies: Using standard methodology and laboratory normative data, serum total calcium (expressed in $\mathrm{mg} / \mathrm{dL}$ ) and inorganic phosphorus (expressed in $\mathrm{mg} / \mathrm{dL}$ ) were measured by MUSC's Clinical ChemistryLaboratory for Charleston, SC subjects and by the University of Rochester's Clinical Chemistry Laboratory for Rochester, NY subjects.

\subsection{Outcomes}

The primary outcome was maternal and infant total circulating $25(\mathrm{OH}) \mathrm{D}$ at baseline by center/latitude, and the secondary outcome was the percent of women and infants who had achieved a concentration of at least 20 $\mathrm{ng} / \mathrm{mL}$, meeting the Institute of Medicine's definition of sufficiency at 4 to 6 weeks postpartum [25]. The primary 
focus of the analysis was to compare the impact of latitude in a group of women and their fully breastfeeding infants of diverse racial and ethnic backgrounds. The primary comparison made was a general test of group differences in the rate of hypovitaminosis D, regardless of race/ethnicity by latitude. Additional secondary outcome measures were blood laboratory parameters: intact PTH (iPTH), serum calcium, and phosphorus, each expressed as the mean \pm standard deviation and as the median and range.

\subsection{Statistical Analysis}

Statistical analysis was performed using SAS version 9.3 (SAS, Cary, NC). Continuous data were expressed as means and standard deviation or median with range, while categorical variables were expressed as proportions. Chi-square analyses were used to test for differences in grouped data. Student's t-test analyses were used to test for differences in continuous variables with a dichotomous grouping that were normally distributed. The Wilcoxon Rank Sum test was used for analyses involving nonparametric variables. Regression models were used to predict $25(\mathrm{OH}) \mathrm{D}$ status. Since $25(\mathrm{OH}) \mathrm{D}$ status had nonparametric distribution, this dependent variable was log-transformed in these models. Correlation analysis was performed by Spearman's Correlation. Significance was set a priori as $\mathrm{p}<0.05$.

\section{RESULTS}

There were 374 fully breastfeeding mothers and their infants enrolled in the study: 203 from Charleston, SC and 171 from Rochester, NY. Of the 374 mother-infant pairs, there were 319 fully or exclusively breastfeeding mothers whose infants were not receiving a vitamin D supplement at the time of their enrollment into the study: 173 from Charleston and 146 from Rochester. All mothers at both sites had a baseline $25(\mathrm{OH}) \mathrm{D} ; 165$ babies from MUSC and 124 from Rochester had a baseline 25(OH)D. There were 17 infants in Charleston and 14 infants in Rochester who were on supplemental vitamin $\mathrm{D}$, so their $25(\mathrm{OH}) \mathrm{D}$ levels are reported separately. One infant was enrolled by maternal report with a gestational age at birth of 36 weeks'; however, later when medical records became available, the confirmed gestational age by obstetrical records was 34 3/7 weeks', representing a protocol deviation from the inclusion criterion of 35 weeks of gestation or greater.

The sociodemographic and clinical characteristics of the cohort are summarized in Table 1. The groups differed by racial/ethnic characteristics in that there were a greater percentage of African American and Hispanic women recruited in Charleston; conversely, there were a greater percentage of Caucasian women recruited in
Rochester. Women in Rochester had received significantly more college education than women in Charleston $(\mathrm{p}<$ $0.0001)$.

The women in the cohort were on average $28.8 \pm 5.9$ years of age (range 18 - 48 years). Maternal BMI was $27.7 \pm 5.0$, and did not differ by site. The majority of women were married and received greater than a high school education. There was a trend where more women in Rochester were enrolled in the spring and summer months that was not found with the Charleston cohort.

As shown in Table 1, the mean gestational age of the infants was $39.3 \pm 1.3$ weeks (range $34-42$ weeks) and differed significantly by site due to the younger gestational age infant included in the Charleston cohort. The mean birth weight of Rochester infants was $\sim 100$ grams greater than those infants born in Charleston $(p=0.05)$. Similarly, head circumference $(p=0.007)$ and length $(p$ $<0.0001$ ) were significantly greater in Rochester infants compared with Charleston infants.

Focusing on the infants who were receiving vitamin D supplementation at the time of their enrollment, there were a total of 31 infants, 17 in Rochester and 14 in Charleston. Fourteen were African American, 15 were Hispanic and 2 were Caucasian. Their baseline 25(OH)D was $31.2 \mathrm{ng} / \mathrm{mL}$ and did differ by race/ethnicity with higher concentrations in Caucasian compared with Hispanic infants. Of the 31 babies on supplement at $4-6$ weeks of age, $6(19 \%)$ had an initial 25(OH)D concentration of $<20 \mathrm{ng} / \mathrm{mL}$. In comparison, of the 258 infants with baseline $25(\mathrm{OH}) \mathrm{D}$ measured who were not on supplement, $190(73.6 \%)$ had an initial 25(OH)D $<20$ $\mathrm{ng} / \mathrm{mL}(\mathrm{p}<0.0001)$. Intact PTH of those on supplement was measured in 21/31 supplemented infants, and was significantly less than those not on supplement: 22.6 vs. $27.1 \mathrm{pg} / \mathrm{mL}$, but this did not reach statistical significance $(\mathrm{p}=0.09)$.

As shown in Table 2(a), the overall mean (standard deviation \pm S.D.) baseline total circulating 25(OH)D for Charleston mothers was $32.4 \pm 14.3$ vs. $32.9 \pm 12.9 \mathrm{ng} / \mathrm{mL}$ for Rochester mothers $(\mathrm{p}=0.5)$. By race, there were distinct differences between the two sites: Caucasian women living in Charleston, SC had significantly higher $25(\mathrm{OH}) \mathrm{D}$ concentrations compared to their counterparts in Rochester, NY ( $p=0.008)$. The reverse relationship was noted in African American and Hispanic women, with improved vitamin D status as measured by total circulating $25(\mathrm{OH}) \mathrm{D}$ in African American women ( $\mathrm{p}=$ $0.009)$ and Hispanic women $(p=0.02)$ living in Rochester, NY.

Maternal intact PTH (iPTH; Table 2(b)) did not differ by site/latitude. When looking at maternal iPTH by site/ latitude substratified by race, there were significant differences only between Caucasian women living at the two latitudes $(p=0.004)$, with lower iPTH in Caucasian 
Table 1. Sociodemographic and clinical characteristics of mothers and infants at baseline by study site.

\begin{tabular}{|c|c|c|c|c|}
\hline Characteristic & $\begin{array}{c}\text { Total Cohort } \\
\text { N }=319\end{array}$ & $\begin{array}{c}\text { Charleston, SC } \\
\qquad \mathbf{N}=173\end{array}$ & $\begin{array}{c}\text { Rochester, NY } \\
\text { N = } 146\end{array}$ & p-value \\
\hline \multicolumn{5}{|l|}{ Race/Ethnicity, N (\%) } \\
\hline African American & $74(23.2)$ & $31(17.9)$ & $43(29.5)$ & \multirow{3}{*}{$<0.000$} \\
\hline Hispanic & $83(26.0)$ & $64(37.0)$ & $19(13.0)$ & \\
\hline Caucasian & $162(50.8)$ & $78(45.1)$ & $84(57.5)$ & \\
\hline \multicolumn{5}{|l|}{ Maternal Age, years } \\
\hline Mean (SD) & $28.8(5.9)$ & $28.8(5.7)$ & $28.9(6.2)$ & \multirow[t]{2}{*}{0.8} \\
\hline Median (range) & $29.0(18.0-48.0)$ & $29.0(18.0-48.0)$ & $29.0(18.0-42.0)$ & \\
\hline \multicolumn{5}{|l|}{ Maternal BMI at enrollment } \\
\hline Mean SD & $27.7(5.0)$ & $27.3(4.7)$ & $28.0(5.2)$ & \multirow[t]{2}{*}{0.2} \\
\hline Median (range) & $26.8(18.0-48.0)$ & $26.9(19.6-41.9)$ & $26.6(18.8-45.8)$ & \\
\hline \multicolumn{5}{|l|}{ Marital Status, N (\%) } \\
\hline Single/Separated/Divorced/Other & $129(40.4)$ & $73(42.2)$ & $56(38.4)$ & \multirow[t]{2}{*}{0.5} \\
\hline Married & $190(59.6)$ & $100(57.8)$ & $90(61.6)$ & \\
\hline \multicolumn{5}{|l|}{ Education, $\mathbf{N}(\%)$} \\
\hline Some College/College Grad & $216(67.7)$ & $99(57.2)$ & $117(80.1)$ & \multirow[t]{2}{*}{$<0.000$} \\
\hline No HS/HS Grad & $106(32.3)$ & $74(42.8)$ & $29(19.9)$ & \\
\hline \multicolumn{5}{|l|}{ Gravity } \\
\hline Median (range) & $2.0(1.0-10.0)$ & $2.0(1.0-9.0)$ & $2.0(1.0-10.0)$ & 0.99 \\
\hline \multicolumn{5}{|l|}{ Parity } \\
\hline Median (range) & $2.0(0.0-6.0)$ & $2.0(1.0-6.0)$ & $2.0(0.0-5.0)$ & 0.005 \\
\hline \multicolumn{5}{|l|}{ Season Enrolled, N (\%) } \\
\hline April - September & $172(53.9)$ & $85(49.1)$ & 87 (59.6) & \multirow[t]{2}{*}{0.06} \\
\hline October - March & $147(46.1)$ & $88(50.9)$ & $59(40.4)$ & \\
\hline \multicolumn{5}{|l|}{ Gestational age (weeks) } \\
\hline Mean (SD) & $39.3(1.3)$ & $39.1(1.4)$ & $39.4(1.1)$ & \multirow[t]{2}{*}{0.01} \\
\hline Median (range) & $39.4(34-42)$ & $39.3(34-42)$ & $39.5(36-41)$ & \\
\hline \multicolumn{5}{|l|}{ Birth weight (grams) } \\
\hline Mean (SD) & $3389.4(480.6)$ & $3341.5(489.0)$ & $3446.1(465.7)$ & \multirow[t]{2}{*}{0.05} \\
\hline Median (range) & $3365.0(1951-4840)$ & $3340.0(1951-4840)$ & $3417.5(2270-4450)$ & \\
\hline \multicolumn{5}{|l|}{ Infant Head Circumference (cm) } \\
\hline Mean (SD) & $37.7(1.5)$ & $37.5(1.5)$ & $37.9(1.3)$ & \multirow[t]{2}{*}{0.007} \\
\hline Median (range) & $37.8(31.0-42.0)$ & $37.5(31.0-41.5)$ & $38.0(34.5-42.0)$ & \\
\hline \multicolumn{5}{|l|}{ Infant length (cm) } \\
\hline Mean (SD) & $54.5(2.6)$ & $53.9(2.5)$ & $55.2(2.5)$ & \multirow[t]{2}{*}{$<0.0001$} \\
\hline Median (range) & $54.5(47.0-63.0)$ & $54.0(47.5-60.5)$ & $55.2(47.0-63.0)$ & \\
\hline
\end{tabular}

women living in Charleston compared to Rochester. There was a trend where iPTH was higher for Hispanic women living in Charleston compared to Rochester, but this did not reach statistical significance $(p=0.06)$.

As shown in Table 2(c), maternal calcium did not differ by site. In comparison, there were regional differences in phosphorus (Table 2(d)) among Hispanic women $(p=0.0006)$ and Caucasian women $(p=0.01)$ with higher values noted in the Charleston cohort.

Although Charleston infants overall had lower 25(OH)D $(15.3 \pm 10.1 \mathrm{ng} / \mathrm{mL})$ compared to those born and living in Rochester, NY(18.1 $\pm 13.6 \mathrm{ng} / \mathrm{mL}$; see Table 3(a)), this did not reach statistical significance. When assessing
25(OH)D by site/latitude and race/ethnicity, African American infants living in Charleston had lower 25(OH)D concentrations than African American infants living in Rochester $(p=0.01)$. There was a trend of higher 25(OH)D among Caucasian infants living in Charleston compared with those living in Rochester, but again, this did not reach statistical significance $(p=0.07)$. Similarly, there were no differences in infant iPTH overall by site (Table 3(b)). By race/ethnicity, the only statistically significant difference noted was between Caucasian infants living in Charleston vs. Rochester: those infants born and living in Rochester had a higher iPTH $(\mathrm{p}=0.05)$.

Infant serum calcium concentrations differed overall 
Table 2. Maternal vitamin D status by study site and racial/ethnic group. (a) maternal total circulating 25(OH)D; (b) maternal intact PTH; (c) maternal serum calcium; (d) maternal phosphorus.

(a)

\begin{tabular}{lccc}
\hline \multicolumn{1}{c}{ Maternal Total Circulating 25(OH)D ng/mL } & Charleston, SC & Rochester, $\mathbf{~ Y ~}$ & p-value (Comparing means) \\
\hline Maternal 25(OH)D ng/mL, N & $\mathrm{N}=173$ & $\mathrm{~N}=146$ & 0.5 \\
All, Mean (SD) & $34.0(14.2)$ & $34.3(12.7)$ & \\
Median (range) & $32.0(5.8-92.1)$ & $33.4(7.8-76.4)$ & 0.009 \\
African American, N & $\mathrm{N}=31$ & $\mathrm{~N}=43$ & \\
Mean (SD) & $21.2(7.3)$ & $28.1(11.2)$ & 0.02 \\
Median (range) & $19.1(9.5-35.6)$ & $27.2(7.8-53.0)$ & \\
Hispanic, N & $\mathrm{N}=64$ & $\mathrm{~N}=19$ & \\
Mean (SD) & $28.2(9.3)$ & $35.5(11.6)$ & \\
Median (range) & $28.7(5.8-51.4)$ & $36.1(13.7-53.3)$ & $\mathrm{N}=84$ \\
Caucasian, N & $\mathrm{N}=78$ & $37.3(12.6)$ & 0.008 \\
Mean (SD) & $43.9(12.8)$ & $36.0(13.0-76.4)$ & \\
Median (range) & $43.0(18.8-92.1)$ & & \\
\hline
\end{tabular}

(b)

\begin{tabular}{lccc}
\hline \multicolumn{1}{c}{ Maternal Intact PTH, $\mathbf{~ g g / m L}$} & Charleston, SC & Rochester, NY & p-value (Comparing means) \\
\hline Maternal iPTH, N & $\mathrm{N}=173$ & $\mathrm{~N}=144$ & 0.2 \\
All, Mean (SD) & $28.4(17.9)$ & $31.4(17.6)$ & \\
Median (range) & $26.6(2.8-165.1)$ & $28.4(3.5-86.9)$ & $\mathrm{N}=43$ \\
African American, N & $\mathrm{N}=31$ & $35.4(18.4)$ & \\
Mean (SD) & $33.9(14.1)$ & $30.9(10.3-86.9)$ & 0.9 \\
Median (range) & $33.0(10.5-82.9)$ & $\mathrm{N}=19$ & \\
Hispanic, N & $\mathrm{N}=64$ & $24.3(13.7)$ & \\
Mean (SD) & $32.6(22.7)$ & $24.2(6.3-57.9)$ & $\mathrm{N}=82$ \\
Median (range) & $29.6(5.2-165.1)$ & $31.0(17.5)$ & 0.004 \\
Caucasian, N & $\mathrm{N}=78$ & $28.1(3.5-79.9)$ & \\
Mean (SD) & $22.7(12.4)$ & & \\
Median (range) & $24.6(2.8-67.4)$ & & \\
\hline
\end{tabular}

(c)

\begin{tabular}{lccc}
\hline Maternal Serum Calcium, $\mathbf{~ m g / d L}$ & Charleston, SC & Rochester, NY & p-value (Comparing means) \\
\hline Maternal Serum Calcium, N & $\mathrm{N}=172$ & $\mathrm{~N}=146$ & 0.5 \\
All, Mean (SD) & $9.4(0.4)$ & $9.3(0.4)$ & \\
Median (range) & $9.3(8.5-10.5)$ & $9.3(8.5-10.4)$ & $\mathrm{N}=43$ \\
African American, N & $\mathrm{N}=31$ & $9.2(0.3)$ & \\
Mean (SD) & $9.2(0.3)$ & $9.2(8.6-10.2)$ & 0.5 \\
Median (range) & $9.1(8.6-9.8)$ & $\mathrm{N}=19$ & \\
Hispanic, N & $\mathrm{N}=63$ & $9.5(0.4)$ & \\
Mean (SD) & $9.3(0.3)$ & $9.6(8.9-10.0)$ & \\
Median (range) & $9.2(8.7-9.9)$ & $\mathrm{N}=84$ & \\
Caucasian, N & $\mathrm{N}=78$ & $9.4(0.4)$ & \\
Mean (SD) & $9.4(0.4)$ & $9.4(8.5-10.4)$ & \\
Median (range) & $9.4(8.5-10.5)$ &
\end{tabular}

(d)

\begin{tabular}{lccc}
\hline \multicolumn{1}{c}{ Maternal Phosphorus, mg/dL } & Charleston, SC & Rochester, $\mathbf{N Y}$ & p-value (Comparing means) \\
\hline Maternal Phosphorus, $\mathbf{N}$ & $\mathrm{N}=171$ & $\mathrm{~N}=146$ & $<0.0001$ \\
All, Mean (SD) & $4.14(0.62)$ & $3.80(0.60)$ & \\
Median (range) & $4.10(2.2-6.1)$ & $3.80(2.3-7.0)$ & 0.6 \\
African American, N & $\mathrm{N}=31$ & $\mathrm{~N}=43$ & \\
Mean (SD) & $3.7(0.5)$ & $3.6(0.4)$ & 0.0006 \\
Median (range) & $3.8(2.2-4.5)$ & $3.3(2.8-4.3)$ & $\mathrm{N}=19$ \\
Hispanic, N & $\mathrm{N}=62$ & $3.8(0.7)$ & \\
Mean (SD) & $4.4(0.6)$ & $3.7(2.7-5.3)$ & 0.01 \\
Median (range) & $4.4(2.6-6.1)$ & $\mathrm{N}=84$ & \\
Caucasian, N & $\mathrm{N}=78$ & $3.9(0.7)$ & \\
Mean (SD) & $4.1(0.6)$ & $3.9(2.3-7.0)$ & \\
Median (range) & $4.1(2.8-5.4)$ & & \\
\hline
\end{tabular}


Table 3. Infant vitamin D status by study site and racial/ethnic group. (a) infant total circulating 25(OH)D; (b) infant intact PTH; (c) infant serum calcium; (d) infant phosphorus.

(a)

\begin{tabular}{lccc}
\hline Infant Total Circulating 25(OH)D ng/mL & Charleston, SC & Rochester, $\mathbf{N Y}$ & p-value \\
\hline Infant 25(OH)D ng/mL, N & $\mathrm{N}=165$ & $\mathrm{~N}=124$ & 0.2 \\
Mean (SD) & $15.3(10.1)$ & $18.1(13.6)$ & \\
Median (range) & $12.9(1.0-42.6)$ & $15.0(1.0-91.0)$ & $\mathrm{N}=37$ \\
African American, N & $\mathrm{N}=30$ & $21.8(18.9)$ & \\
Mean (SD) & $9.5(7.6)$ & $19.6(1.0-91.0)$ & \\
Median (range) & $7.7(1.0-32.2)$ & $\mathrm{N}=17$ & \\
Hispanic, N & $\mathrm{N}=63$ & $15.1(12.3)$ & \\
Mean (SD) & $13.1(9.5)$ & $10.5(1.0-36.8)$ & \\
Median (range) & $11.2(1.0-37.8)$ & $\mathrm{N}=70$ & \\
Caucasian, N & $\mathrm{N}=72$ & $16.8(9.7)$ & \\
Mean (SD) & $19.7(9.8)$ & $14.6(1.7-43.0)$ & 0.07 \\
Median (range) & $18.6(3.1-42.6)$ & & \\
\hline
\end{tabular}

(b)

\begin{tabular}{lccc}
\hline Infant Intact PTH (iPTH), $\mathbf{~ p g / m L ~}$ & Charleston, SC & Rochester, NY & p-value \\
\hline Infant iPTH, N & $\mathrm{N}=68$ & $\mathrm{~N}=81$ & 0.4 \\
Mean (SD) & $25.4(14.2)$ & $28.5(25.7)$ & \\
Median (range) & $21.5(3.6-60.6)$ & $23.7(4.6-201.6)$ & $\mathrm{N}=22$ \\
African American, N & $\mathrm{N}=15$ & $35.8(35.9)$ & 0.3 \\
Mean (SD) & $37.6(15.5)$ & $22.9(5.7-201.6)$ & \\
Median (range) & $33.5(11.8-60.6)$ & $\mathrm{N}=9$ & 0.4 \\
Hispanic, N & $\mathrm{N}=29$ & $35.9(39.5)$ & \\
Mean (SD) & $24.1(12.1)$ & $20.2(9.5-136.8)$ & $\mathrm{N}=50$ \\
Median (range) & $20.5(3.6-53.1)$ & $24.0(10.8)$ & 0.05 \\
Caucasian, N & $\mathrm{N}=24$ & $23.6(4.6-51.5)$ & \\
Mean (SD) & $19.4(11.3)$ & \\
Median (range) & $17.6(4.6-53.9)$ &
\end{tabular}

(c)

\begin{tabular}{lccc}
\hline \multicolumn{1}{c}{ Infant Serum Calcium, $\mathbf{~ m g / d L}$} & Charleston, SC & Rochester, $\mathbf{N Y}$ & p-value \\
\hline Infant Serum Calcium, $\mathbf{N}$ & $\mathrm{N}=104$ & $\mathrm{~N}=128$ & 0.0006 \\
Mean (SD) & $10.2(0.4)$ & $10.4(0.4)$ & \\
Median (range) & $10.2(9.1-11.0)$ & $10.4(9.4-11.3)$ & 0.06 \\
African American, N & $\mathrm{N}=19$ & $\mathrm{~N}=35$ & \\
Mean (SD) & $10.1(0.4)$ & $10.3(0.4)$ & \\
Median (range) & $10.0(9.4-10.9)$ & $10.4(9.6-11.1)$ & \\
Hispanic, N & $\mathrm{N}=44$ & $\mathrm{~N}=17$ & \\
Mean (SD) & $10.2(0.4)$ & $10.4(0.5)$ & \\
Median (range) & $10.2(9.1-11.0)$ & $10.3(9.4-11.3)$ & \\
Caucasian, N & $\mathrm{N}=41$ & $\mathrm{~N}=76$ & \\
Mean (SD) & $10.3(0.3)$ & $10.4(0.3)$ & \\
Median (range) & $10.3(9.6-10.9)$ & $10.4(9.5-11.2)$ & \\
\hline
\end{tabular}

(d)

\begin{tabular}{lccc}
\hline \multicolumn{1}{c}{ Infant Phosphorus, $\mathbf{m g}$ /dL } & Charleston, SC & Rochester, NY & p-value \\
\hline Infant Phosphorus, $\mathbf{N}$ & $\mathrm{N}=102$ & $\mathrm{~N}=127$ & 0.6 \\
Mean (SD) & $6.5(0.5)$ & $6.5(0.5)$ & \\
Median (range) & $6.5(5.1-7.8)$ & $6.5(4.9-7.8)$ & $\mathrm{N}=33$ \\
African American, N & $\mathrm{N}=18$ & $6.4(0.6)$ & 0.9 \\
Mean (SD) & $6.4(0.6)$ & $6.5(4.9-7.5)$ & \\
Median (range) & $6.5(5.2-7.4)$ & $\mathrm{N}=19$ & \\
Hispanic, N & $\mathrm{N}=44$ & $6.4(0.4)$ & 0.6 \\
Mean (SD) & $6.5(0.6)$ & $6.4(5.5-7.2)$ & $\mathrm{N}=77$ \\
Median (range) & $.5(5.5-7.8)$ & $6.5(0.5)$ & 0.9 \\
Caucasian, N & $\mathrm{N}=40$ & $6.5(5.6-7.8)$ & \\
Mean (SD) & $6.5(0.5)$ & & \\
Median (range) & $6.5(5.1-7.6)$ & & \\
\hline
\end{tabular}


by site with higher values in Rochester infants compared with Charleston infants (Table 3(c); $p=0.0006$ ). By race/ethnicity, there was a trend where Rochester infants within each subgroup had higher values than their Charleston counterparts. There were no statistically significant differences in phosphorus by site or by race/ethnicity (Table 3(d)).

By season, there was a trend where Rochester mothers had significantly higher mean $25(\mathrm{OH}) \mathrm{D}$ concentrations during spring and summer months than Charleston mothers $(\mathrm{p}=0.06$; Table 4(a)). Similarly, Rochester infants had higher mean $25(\mathrm{OH}) \mathrm{D}$ concentrations during spring/ summer months than Charleston infants $(\mathrm{p}=0.04$, Table 4(b)).

In assessing the relationship between maternal iPTH and $25(\mathrm{OH}) \mathrm{D}$, there was a significant correlation $(\mathrm{r}=$ $-0.32)$ : the regression model showed that as $25(\mathrm{OH}) \mathrm{D}$ increased by $1 \mathrm{ng} / \mathrm{mL}$, iPTH decreased by $0.24 \mathrm{pg} / \mathrm{mL}$ (overall $\mathrm{p}<0.0001$; Charleston $\mathrm{p}=<0.0001$; Rochester $\mathrm{p}=0.0001)$. This relationship was similar by site and by race/ethnicity. A similar relationship was found between infant $25(\mathrm{OH}) \mathrm{D}$ and $\mathrm{PTH}(\mathrm{r}=-0.35)$ : the regression model showed that as $25(\mathrm{OH}) \mathrm{D}$ increased by $1 \mathrm{ng} / \mathrm{mL}$, iPTH decreased by $0.13 \mathrm{pg} / \mathrm{mL}$ (overall $\mathrm{p}=0.0008$; Charleston $\mathrm{p}=0.003$; Rochester $\mathrm{p}=0.02$ ).

In exploring the relationships between infant and maternal vitamin D status, certain relationships became evident: Infant $25(\mathrm{OH}) \mathrm{D}$ concentrations were significantly correlated with maternal 25(OH)D (Charleston: $r=0.65$, $\mathrm{p}<0.0001$; Rochester: $\mathrm{r}=0.42, \mathrm{p}<0.0001)$. Infant $25(\mathrm{OH}) \mathrm{D}$ also was weakly correlated with maternal $\mathrm{iPTH}$ for Charleston infants: $(\mathrm{r}=0.28, \mathrm{p}=0.0003)$, but not Rochester infants $(\mathrm{r}=0.12, \mathrm{p}=0.17)$. There appeared to be a more significant association between maternal $25(\mathrm{OH}) \mathrm{D}$ and infant iPTH (Charleston, $r=0.45, \mathrm{p}=0.0001$; Rochester, $r=0.33, p=0.002$ ).

In a multiple regression model, when predicting maternal total circulating $25(\mathrm{OH}) \mathrm{D}$ concentration (using log transformed values for nonequal distribution) after controlling for race/ethnicity, insurance status, education, BMI, site/latitude, and season in the regression model, being Caucasian ( $p<0.0001)$, season $(\mathrm{p}<0.0001)$, and BMI $(\mathrm{p}<0.0001)$ were independently positively associated with maternal $25(\mathrm{OH}) \mathrm{D}$. Site/latitude was no longer significant in this model.

Using multiple regression to predict baseline infant 25(OH)D using log transformation and controlling for race/ethnicity, insurance status, season, site/latitude, education, BMI, and any single birth measurement (birth weight or gestational age, or birth head circumference, or birth length), latitude had no association with baseline infant $25(\mathrm{OH}) \mathrm{D}(\mathrm{p}=0.51)$. Being Caucasian $(\mathrm{p}=0.0005)$ and summer season $(\mathrm{p}<0.0001)$ were independently positively associated with infant baseline $25(\mathrm{OH}) \mathrm{D}$ concentration.

When using the Institute of Medicine's total circulating $25(\mathrm{OH}) \mathrm{D}$ threshold for sufficiency in infants of 20 $\mathrm{ng} / \mathrm{mL}$ (see Table 5), regardless of race/ethnicity (or any other factor tested), mothers of infants with a baseline $25(\mathrm{OH}) \mathrm{D}>20(\mathrm{~N}=92)$ had a mean $25(\mathrm{OH}) \mathrm{D}$ of $41.8 \pm$ $14.4 \mathrm{ng} / \mathrm{mL}$ (median 41.3; range $7.8-92.1 \mathrm{ng} / \mathrm{mL}$ ). When using a higher $25(\mathrm{OH}) \mathrm{D}$ threshold for sufficiency of 32 $\mathrm{ng} / \mathrm{mL}$, regardless of race/ethnicity (or any other factor

Table 4. Maternal and infant vitamin D status by season and Site. (a) Maternal Total Circulating 25(OH)D by season and site; (b) infant total Cordially, circulating $25(\mathrm{OH}) \mathrm{D}$ by season and site.

(a)

\begin{tabular}{lccc}
\hline \multicolumn{1}{c}{$\begin{array}{c}\text { Maternal Total Circulating } \\
\text { 25(OH)D ng/mL }\end{array}$} & Charleston, SC & Rochester, $\mathbf{~ Y ~}$ & p-value \\
\hline April-September, $\mathbf{N}$ & $\mathrm{N}=85$ & $\mathrm{~N}=87$ & 0.06 \\
Mean (SD) & $34.9(14.5)$ & $38.3(13.2)$ & \\
Median (range) & $33.8(9.5-92.1)$ & $38.9(10.6-76.4)$ & $\mathrm{N}=59$ \\
October-March, N & $\mathrm{N}=88$ & $28.4(9.0)$ & 0.1 \\
Mean (SD) & $33.1(13.9)$ & $28.1(7.8-50.7)$ & \\
Median (range) & $30.9(5.8-67.6)$ & \\
\hline
\end{tabular}

(b)

\begin{tabular}{lccc}
\hline \multicolumn{1}{c}{$\begin{array}{c}\text { Infant Total Circulating } \\
\text { 25(OH)D ng/mL }\end{array}$} & Charleston, SC & Rochester, $\mathbf{~ Y ~}$ & p-value \\
\hline April-September, $\mathbf{N}$ & $\mathrm{N}=82$ & $\mathrm{~N}=74$ & 0.04 \\
Mean (SD) & $17.7(10.7)$ & $21.9(13.9)$ & \\
Median (range) & $15.8(1.0-42.6)$ & $19.8(1.0-91.0)$ & $\mathrm{N}=50$ \\
October-March, $\mathbf{N}$ & $\mathrm{N}=83$ & $12.3(10.8)$ & 0.5 \\
Mean (SD) & $13.0(8.9)$ & $8.6(1.0-49.9)$ & \\
Median (range) & $11.5(1.0-37.9)$ & \\
\hline
\end{tabular}


Table 5. Maternal and infant vitamin $\mathrm{d}^{\text {deficiency }}{ }^{1}$ rates by site.

\begin{tabular}{|c|c|c|c|c|}
\hline Characteristic & $\begin{array}{c}\text { Total Cohort } \\
\text { N }=319\end{array}$ & $\begin{array}{c}\text { Charleston, SC } \\
\mathbf{N}=173\end{array}$ & $\begin{array}{c}\text { Rochester, NY } \\
\mathrm{N}=146\end{array}$ & p-value \\
\hline Maternal Circulating $25(\mathrm{OH}) \mathrm{D}<20 \mathrm{ng} / \mathrm{mL}, \mathrm{N}(\%)$ & $46(14.4)$ & $29(16.7)$ & $17(11.6)$ & 0.2 \\
\hline Infant Circulating 25(OH)D $<20 \mathrm{ng} / \mathrm{mL}, \mathrm{N}(\%)^{2}$ & $196(67.8)$ & $115(69.7)$ & $1(65.3)$ & 0.4 \\
\hline
\end{tabular}

${ }^{1}$ Vitamin D deficiency as defined by total circulating $25(\mathrm{OH}) \mathrm{D}$ using the Institute of Medicine's threshold of $20 \mathrm{ng} / \mathrm{mL} .{ }^{2}$ Excludes those infants who were taking vitamin D supplements at the time of study enrollment.

tested), mothers of infants with a baseline $25(\mathrm{OH}) \mathrm{D}>32$ $(\mathrm{N}=31)$ had a mean $25(\mathrm{OH}) \mathrm{D}$ of $45.7 \pm 16.4 \mathrm{ng} / \mathrm{mL}$ (median 42.2; range $12.2-92.1 \mathrm{ng} / \mathrm{mL}$ ).

\section{DISCUSSION}

In this study of baseline vitamin D status at four-to-six weeks postpartum in fully lactating women and their infants participating in a NICHD-sponsored vitamin D supplementation trial during lactation, higher latitude adversely affected vitamin D status only in lactating Caucasian women. African American and Hispanic women and infants living in Rochester compared to Charleston had improved vitamin D status, an effect that was no longer significant when controlling for socioeconomic factors and season. Overall, there was significant vitamin $\mathrm{D}$ deficiency at baseline in lactating mothers, and far greater deficiency in their infants. Maternal baseline $25(\mathrm{OH}) \mathrm{D}$ concentration remained positively associated with being Caucasian, BMI and summer months. Breastfeeding infant vitamin D status mirrored maternal status and remained positively associated with being Caucasian and summer months. Those infants who had been on a vitamin D supplement at the time of enrollment in the study had markedly improved vitamin D status compared to those infants not on supplement, but represented a significant minority of the cohort.

Because sunlight exposure traditionally has been correlated with vitamin D status and higher latitudes have diminishing sunlight exposure for increasing months during the year, it was predicted that those living in higher latitudes would have a greater risk of vitamin D deficiency. Yet, with changes in lifestyles with less time spent outdoors and the use of sunscreen that blocks the synthesis of vitamin $\mathrm{D}$, there have been reports of vitamin D deficiency even at more southerly latitudes $(7,8)$. Our findings are consistent with these findings. African American and Hispanic women living in Charleston, $\mathrm{SC}$ at a lower latitude had worse vitamin D status compared to women of the same racial/ethnic groups living at a higher latitude in Rochester, NY. Women in Charleston, SC were poorer and less educated than those women living in Rochester, NY. When accounting for such differences in socioeconomic status, the differences in vitamin D status were no longer present but did not approach the differences seen between Caucasian women. Caucasian women living in a more southerly clime had improved vi- tamin D status compared to those Caucasian women living at more northerly latitude.

The need for vitamin D supplementation of the infant when mother herself is not vitamin D replete is underscored by this study. The rate of vitamin D deficiency using the Institute of Medicine's definition of vitamin D deficiency was highest among unsupplemented infants- $73.6 \%$ compared to $19 \%$ who were receiving a supplement. Of those fully breastfeeding infants, despite the American Academy of Pediatrics' recommendation issued in 2008 that all breastfeeding infants receive 400 IU vitamin D/day [9], only $9.7 \%$ of the infants were on supplement at $4-6$ weeks postpartum. There appears to be a gap between the recommendation and what health care providers in two diverse locations and latitudes are implementing. Others have reported similar low adherence to implementing this recommendation [26].

Limitations of this study are that there were not equal numbers of women by race/ethnicity enrolled at the two study sites: there was a higher percentage of Caucasian women compared to African American and Hispanic women enrolled at the Rochester site and a more evenly divided percentage of the three groups at the Charleston site, reflecting sociodemographic differences of the two regions. With smaller numbers of women in each subgroup in Rochester, analyses were limited by sample size constraints. Despite these limitations, however, the differences in vitamin D status by latitude could be assessed and provided important findings that are applicable to lactating women today.

\section{CONCLUSION}

In summary, there was a significant vitamin $\mathrm{D}$ deficiency among a cohort of women and their infants living at two diverse latitudes: Charleston, SC and Rochester, NY. Given the higher rate of vitamin D deficiency among African American and Hispanic women and their infants living at a lower latitude, conclusions about vitamin D status based on latitude alone may be faulty.

\section{REFERENCES}

[1] Ladizesky, M., Lu, Z., Oliveri, B., San Roman, N., Diaz, S., Holick, M.F., et al. (1995) Solar ultraviolet B radiation and photoproduction of vitamin D3 in central and southern areas of Argentina. Journal of bone and mineral re- 
search: The Official Journal of the American Society for Bone and Mineral Research, 10, 545-549.

http://dx.doi.org/10.1002/jbmr.5650100406

[2] Holick, M.F. (1981) The cutaneous photosynthesis of previtamin D3: A unique photoendocrine system. Journal of Investigative Dermatology, 77, 51-58.

http://dx.doi.org/10.1111/1523-1747.ep12479237

[3] Webb, A.R., Kline, L. and Holick, M.F. (1988) Influence of season and latitude on the cutaneous synthesis of vitamin $\mathrm{D}_{3}$ synthesis in human skin. The Journal of Clinical Endocrinology \& Metabolism, 67, 373-378. http://dx.doi.org/10.1210/jcem-67-2-373

[4] Oliveri, M.B., Ladizesky, M., Mautalen, C.A., Alonso, A. and Martinez, L. (1993) Seasonal variations of 25 hydroxyvitamin D and parathyroid hormone in Ushuaia (Argentina), the southernmost city of the world. Bone Miner, 20, 99-108.

http://dx.doi.org/10.1016/S0169-6009(08)80041-4

[5] Porojnicu, A.C., Lagunova, Z., Robsahm, T.E., Berg, J.P., Dahlback, A. and Moan, J. (2007) Changes in risk of death from breast cancer with season and latitude: Sun exposure and breast cancer survival in Norway. Breast Cancer Research and Treatment, 102, 323-328.

http://dx.doi.org/10.1007/s10549-006-9331-8

[6] Basile, L.A., Taylor, S.N., Wagner, C.L., Quinones, L. and Hollis, B.W. (2007) Neonatal vitamin D status at birth at latitude 32 degrees 72': Evidence of deficiency. Journal of Perinatology, 27, 568-571.

http://dx.doi.org/10.1038/sj.jp.7211796

[7] Hamilton, S.A., McNeil, R., Hollis, B.W., Davis, D.J., Winkler, J., Cook, C., et al. (2010) Profound vitamin D deficiency in a diverse group of women during pregnancy living in a sun-rich environment at latitude 32 degrees $\mathrm{N}$. International Journal of Endocrinology, 917428.

[8] Johnson, D.D., Wagner, C.L., Hulsey, T.C., McNeil, R.B., Ebeling, M. and Hollis, B.W. (2010) Vitamin D deficiency and insufficiency is common during pregnancy. American Journal of Perinatology, 28, 7-12. http://dx.doi.org/10.1055/s-0030-1262505

[9] Wagner, C.L. and Greer, F.R. (2008) Prevention of rickets and vitamin D deficiency in infants, children, and adolescents. Pediatrics, 122, 1142-1152. http://dx.doi.org/10.1542/peds.2008-1862

[10] Wagner, C.L., Hulsey, T.C., Fanning, D., Ebeling, M. and Hollis, B.W. (2006) High-dose vitamin D3 supplementation in a cohort of breastfeeding mothers and their infants: A 6-month follow-up pilot study. Breastfeed Medicine, 1, 59-70. http://dx.doi.org/10.1089/bfm.2006.1.59

[11] Hollis, B.W. and Wagner, C.L. (2004) Assessment of dietary vitamin D requirements during pregnancy and lactation. The American Journal of Clinical Nutrition, 79, 717 726.

[12] Hollis, B.W. and Wagner, C.L. (2011) The vitamin D requirement during human lactation: The facts and IOM's "utter" failure. Public Health Nutrition, 14, 748-749. http://dx.doi.org/10.1017/S1368980011000309

[13] Hollis, B.W., Johnson, D., Hulsey, T.C., Ebeling, M. and Wagner, C.L. (2011) Vitamin D supplementation during pregnancy: Double-blind, randomized clinical trial of safety and effectiveness. Journal of Bone and Mineral Research: The Official Journal of the American Society for Bone and Mineral Research, 26, 2341-2357. http://dx.doi.org/10.1002/jbmr.463

[14] Greer, F.R., Hollis, B.W., Cripps, D.J. and Tsang, R.C. (1984) Effects of maternal ultraviolet B irradiation on vitamin D content of human milk. Journal of Pediatrics, 105, 431-433. http://dx.doi.org/10.1016/S0022-3476(84)80021-9

[15] Greer, F.R., Hollis, B.W. and Napoli, J.L. (1984) High concentrations of vitamin $\mathrm{D}_{2}$ in human milk associated with pharmacologic doses of vitamin $\mathrm{D}_{2}$. Journal of Pediatrics, 105, 61-64.

http://dx.doi.org/10.1016/S0022-3476(84)80361-3

[16] Hollis, B. and Wagner, C. (2004) Vitamin D requirements during lactation: High-dose maternal supplementation as therapy to prevent hypovitaminosis D in both mother and nursing infant. The American Journal of Clinical Nutrition, S80, 1752-1758.

[17] Gartner, L. and Greer, F. (2003) American academy of pediatrics. Section on breastfeeding medicine and committee on nutrition. Prevention of rickets and vitamin D deficiency: New guidelines for vitamin D intake. Pediatrics, 111, 908-910. http://dx.doi.org/10.1542/peds.111.4.908

[18] Labbok, M.H. and Krasovec, K. (1990) Toward consistency in breastfeeding definitions. Studies in Family Planning, 21, 226-230. http://dx.doi.org/10.2307/1966617

[19] Coffin, C.F., Labbok, M.H. and Belsey, M. (1997) Breastfeeding definitions. Contraception, 55, 323-325. http://dx.doi.org/10.1016/S0010-7824(97)00039-5

[20] Hollis, B.W., Kamerud, J.Q., Selvaag, S.R. and Lorenz, J.D. (1993) Determination of vitamin D status by radioimmunoassay with a 125I-labeled tracer. Clinical Chemistry, 39, 529-533.

[21] Laboratories, M.C. (2004) Laboratory reference data. Mayo Clinic, Rochester.

[22] Hollis, B.W. and Wagner, C.L. (2005) Normal serum vitamin D levels. The New England Journal of Medicine, 352, 515-516. http://dx.doi.org/10.1056/NEJM200502033520521

[23] Hollis, B. (2005) Circulating 25-hydroxyvitamin D levels indicative of vitamin D sufficiency: Implications for establishing a new effective dietary intake recommendation for vitamin D. The Journal of Nutrition, 135, 317-322.

[24] Vieth, R., Ladak, Y. and Walfish, P. (2003) Age-related changes in the 25-hydroxyvitamin $\mathrm{D}$ versus parathyroid hormone relationship suggest a different reason why older adults require more vitamin D. The Journal of Clinical Endocrinology \& Metabolism, 88, 185-191.

[25] Food and Nutrition Board (2010) Standing Committee on the scientific evaluation of dietary reference intakes. Dietary reference intakes for vitamin D and calcium. National Academy Press, Washington DC.

[26] Shaikh, U. and Alpert, P. (2004) Practices of vitamin D recommendation in Las Vegas, Nevada. Journal of Medical Microbiology, 20, 56-61. http://dx.doi.org/10.1177/0890334403260617 